\title{
Time Series Forecasting Of Water Quality Of River Godavari
}

\author{
Mahesh Kumar.Akkaraboyina ${ }^{1}$ prof B.S.N.Raju ${ }^{2}$ \\ ${ }^{1}$ Research Scholar, Civil Engineering Department, Andhra University, Visakhapatnam, India \\ ${ }^{2}$ Research Guide, Head of Civil Engineering Department, Andhra University Visakhapatnam, India.
}

\begin{abstract}
The research and developmental activities for generating new water quality models provide a valuable source of knowledge in the fields of water resources and environmental engineering. Due to limited water quality data and high cost of water quality monitoring, the data based modeling approaches are being extensively used. This paper presents the forecasted monthly values of water quality parameters viz., $\mathrm{pH}$, Water Temperature and Dissolved Oxygen of River Godavari at Rajahmundry water quality monitoring station, Andhra Pradesh, India. Time series methods of forecasting were used for the predictions of parameter values. The predicted values are compared with actual measured observations using statistical performance tests. The results indicated that the proposed models were performing well. The MAE, RMSE and MAPE values, for $p H$ 0.249, 0.359and 3.228; for Water Temperature 0.94, 1.18 and 3.24 and for Dissolved Oxygen 0.56, 0.67 and 7.52, respectively. The forecasted water quality parameter observations for the study period (2009-2012) and the future period (2012-2015) showed seasonal trend pattern which indicated quality of water is greatly influenced by the seasonal inflows. The time series forecasting methods with allowable error limits can be used to assess the future water quality and for taking protection measure for conservation of the river.
\end{abstract}

Keywords: Rajahmundry, River Godavari, Time Series Forecasting, Water Quality Parameters

\section{Introduction:}

River water quality models are used extensively in research as well as in the design and management measures. River water quality models seek to describe the spatial and temporal changes of constituents of concern. Successful river water quality modeling requires the specification of an appropriate model structure and process formulation. Therefore, appropriate river water quality management strategies aimed at controlling and improving water quality should be seriously considered. At least, these strategies should not reduce further degradation of current water quality in rivers. To manage river water quality in the most effective and efficient way, the cause and effect relationships of the river system must first be investigated.

Due to the critical issues on water pollution and the scarcity of water resources, various model systems are being applied despite of their limitations. The present situation is that the different countries are applying different models of water quality assessment system. Based on the limitations of the existing assessment systems, it is appropriate to explore other approaches that can be more flexible, robust to noisy data, and adaptable to new form of environmental data, in order to provide direct and prompt results for classifying of river water quality.

Rivers and streams are highly heterogeneous in spatial as well as temporal scales and several investigators have studied the physio-chemical dynamics of rivers. There are several studies relating to the assessment of water quality of Rivers. In India Najafpour.Sh et al., [1]; Priyanka Trivedi et al., [2]; Nikhil Raj and P.A.Azeez [3]; Muhamed Ashraf.P and M.K.Mukundan [4]; A.G.Murugesan et al.,[5]; Mariappan., et al., [6] and many others have conducted studies related to water quality. Pioneer studies were conducted by Miller, W.W.Joung, et al., [7], N. Singkran, et al.,[8] and others outside India. Some researchers viz., Rita .N.Kumar, et al., [9], Tiwari, T.N. and ,Mishra.M.,[10], Ashwani Kumar and Anish Dua, [11] have assessed the water quality variation to evaluate the water quality index of Rivers.

\section{Study area:}

The Godavari is the largest river in south India and ranks 3rd among the Indian rivers, flows $1465 \mathrm{Km}$ and empties into the Bay of Bengal. It rises in the Sahayadri hills, in Maharastra state and it reaches Andhra Pradesh receiving water from the Manjira, the Pranahita (which itself is itself formed by the confluence of the three rivers viz., the Wardha, the Painganga and the Wainganga); the Mannair, the Indravathi and the Sabari. The last major tributary of Godavari is Sabari which falls into Godavari about $1268 \mathrm{Km}$ from its source. After the confluence with Sabari, the Godavari begins to wind amongst the hills of the Eastern Ghats, which gradually close on it, till it is forced to go through a picturesque gorge at Papikonda which for five kilometers is as narrow as $60 \mathrm{mts}$ to $90 \mathrm{mts}$ at flood time. The river enters the Andhra Pradesh state near Bhadrachalam and flows along Godhavarikhani, Rajahmundry, Kovvur, Tallapudi and Narsapur in a southeast direction until it empties into the Bay of Bengal through two mouths. The upper waters of the Godavari are scarcely utilized for irrigation, but the 
entire delta has turned into a garden of perennial crops by means of the anicut at Dowlaiswaram, constructed by Sir Arthur Cotton 145 years ago.

Rajahmundry is located at $16.98^{\circ} \mathrm{N} 81.78^{\circ} \mathrm{E}$ with an average elevation of 14 meters ( 45 feet). It is the fourth largest city in Andhra Pradesh, on the banks of the River Godavari, well known as the Cultural Capital of Andhra Pradesh. The city's origins can be traced back to the rule of the Chalukya king Rajaraja Narendra who reigned around 1022 A.D after whom it is named Rajamahendri or Rajamahendravaram. Later renamed as Rajahmundry during the rule of the British, for whom the city was the headquarters of the Godavari district. The present research work has been taken up to assess the seasonal water quality variation and to forecast the fate of River Godavari due to various developmental activities taking place in and around the monitoring stations. The objectives of the present paper are (1) to discuss the seasonal variations of the water quality parameters (2) to compare the predicted and actual measured observation (3) To forecast the future seasonal variations of the parameter in concern at the Rajahmundry station

\section{Materials and Methods}

Water samples were collected once every month from the Rajahmundry Water Quality Monitoring Station, from the surface waters of the River Godavari. The water samples were analyzed at the Water Quality Level -II Laboratory, Dowlaiswaram, Irrigation \& CAD Department, Government of Andhra Pradesh, India; as per the standard methods of Practice. Various water quality parameters were studied during the study period (2009 to 2012) and historic data obtained from the Hydrology Department, Govt of Andhra Pradesh, was used in the analysis. The historic water quality data of the monitoring station was used to forecast the Timeseries model (2009-2012) data of water quality parameters. The predicted values of respective parameters were compared with the actual measured values, to test the performance of the developed model. The overall available actual measured data of the monitoring station was used to forecast the Timeseries model (2012-2015).

\section{1 pH Model}

\section{Results and Discussions:}

The $\mathrm{pH}$ of water is a measurement of the concentration of $\mathrm{H}+$ ions, using a scale that ranges from 0 to 14. A pH of 7 is indicates neutral and concentrations of $\mathrm{H}+$ and $\mathrm{OH}$ - ions are equal. For every one unit change in $\mathrm{pH}$, there is approximately a ten-fold change in acidity or alkalinity. Therefore, a pH of 4 is 10 times more acidic than a pH of 5. Similarly, a $\mathrm{pH}$ of 9 is 10 times more alkaline than a pH of 8 and 100 times more alkaline than a $\mathrm{pH}$ of 7. Pure deionized water is neutral, with a $\mathrm{pH}$ of 7. Natural water usually has a pH between 6.5 and 8.5. The natural variations in $\mathrm{pH}$, are due to human influences. Industrial effluents, acid rains etc.

The variations of the $\mathrm{pH}$ parameter values during the study period 2009-2012 are illustrated in the Fig:1(a). The variations of the forecasted $\mathrm{pH}$ values for the future period 2012-2015 are shown in Fig: 1(b). The descriptive statistics of the $\mathrm{pH}$ values predicted from the Timeseries models and Actual measured values are tabulated below. The forecasted and actual measured values exhibited seasonal variations and followed a linear trend pattern. Variations do exist between the predicted and observed value, though slight variations existed the $\mathrm{pH}$ values remained almost same, indicating that the developed models are performing well. The results of the statistical performance test revealed that the $\mathrm{MAE}=0.56, \mathrm{RMSE}=0.67$ and $\mathrm{MAPE}=7.52$; which shows that the predicted values are reliable. It is to be concluded that the forecasted values for the future period Shown a decreasing trend during Southwest monsoon (Jun to Sep) and Northeast monsoon (Oct to Dec) seasons. An increasing trend was observed during the winter (Jan to Feb) and summer (Mar to May) seasons respectively.

Table1: Descriptive statistics of pH during Study period 09-12) and Future period (12-15)

\begin{tabular}{|c|c|c|c|c|c|}
\hline Developed Model & Min & Max & Mean & Std. Dev & Var. \\
\hline Actual Measured & 7.40 & 8.20 & 7.91 & 7.90 & 0.08 \\
\hline Time Series 2009-12 & 7.86 & 7.88 & 7.87 & 7.87 & 0.00 \\
\hline Time Series 2012-15 & 6.96 & 9.31 & 7.96 & 7.64 & 0.11 \\
\hline
\end{tabular}

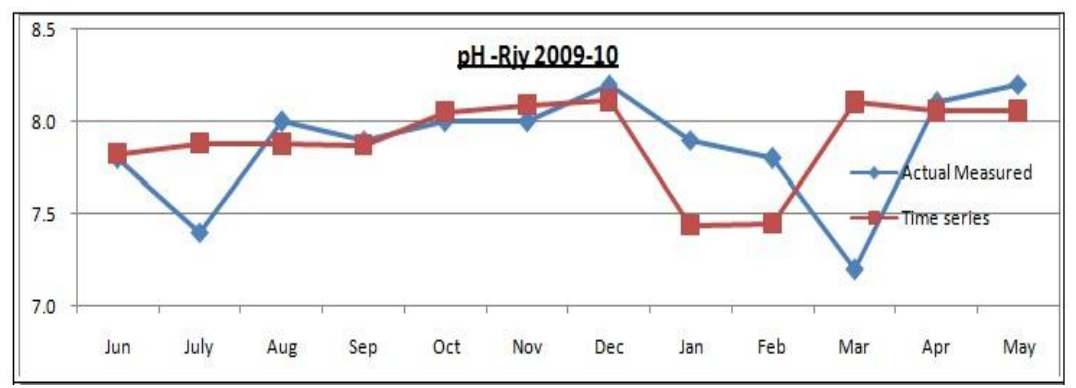




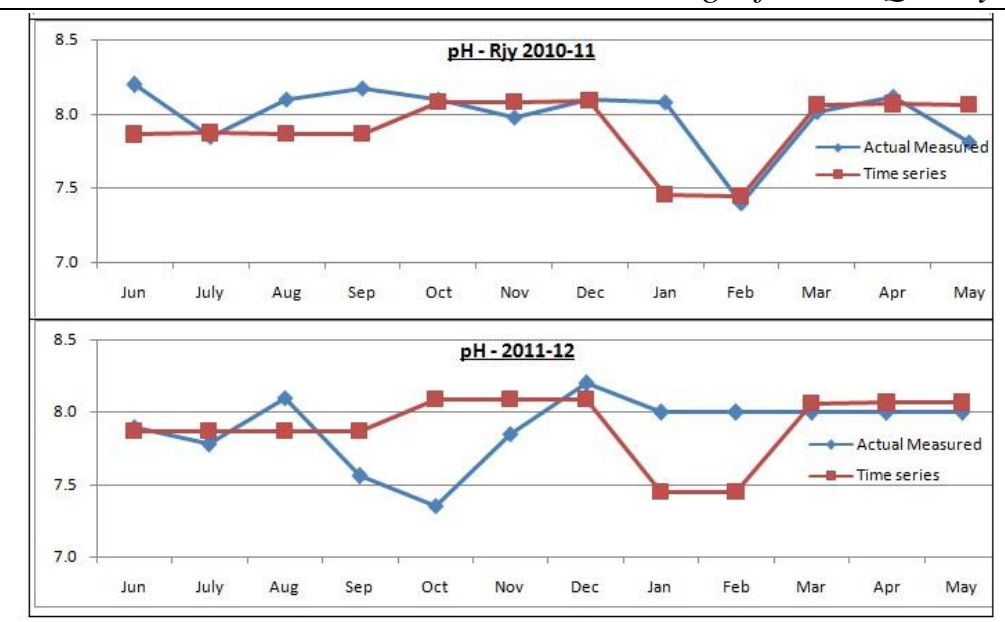

Figure1(a): Graphs showing the variations of $\mathrm{pH}$ during the study period (2009-2012)

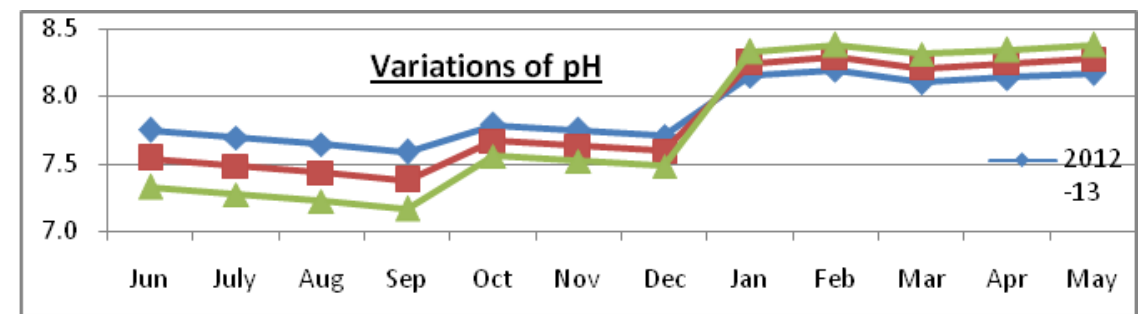

Figure1(b): Graph showing the variations of pH during the Future Period (2012-2015)

\subsection{Water Temperature:}

Water temperature is an important water quality parameter which influences the Dissolved Oxygen, BOD, COD levels etc. The solubility of gases increases with decreasing temperature. The temperature in water influences the aquatic life inhibiting the water course. Thermal pollution occurs when humans change the temperature of a body of water. The most common point source of thermal pollution is cooling water, which is used to cool machinery. Thermal pollution may also be caused by stormwater runoff from warm surfaces such as streets and parking lots. Soil erosion is another cause, since it can cause cloudy conditions in a water body. Cloudy water absorbs the sun's rays, resulting in a rise in water temperature. Various factor affect the temperature of water, which inturn affects the overall health of the river water.

The variations of the water temperature parameter during the study period (2009-2012) and the future period 2012-2015 are shown in Fig: 1 (a) \& 1(b) below. The descriptive statistics of the values predicted from the Timeseries models and Actual measured values are tabulated below. Strong seasonal trend was obtained for the time series predicted values. The actual measured also indicated seasonal trend and variations were also observed. These variations are occurred due to the lower values reported in the historic data influenced the predicted values which varied from the actual measured values. This indicated that the water temperatures are found increasing.

The results of the statistical performance test MAE $=0.249$, RMSE $=0.359$ and MAPE $=3.228$ were obtained. It may be concluded that the predicted values are reliable and the performance of the developed models is satisfactory. The forecasted values for the future period showed an increasing trend during Southwest monsoon (Jun to Sep) and decreasing trend was observed during the Summer (Mar to May) season. The trend followed almost same pattern during Northeast Monsoon (Oct to Dec) and Winter (Jan to Feb) seasons respectively.

Table 2: Descriptive statistics of Water Temp during Study period (09-12) and Future period (12-15)

\begin{tabular}{|c|c|c|c|c|c|}
\hline Developed Model & Min & Max & Mean & Std. Dev & Var. \\
\hline Actual Measured & 7.40 & 8.20 & 7.91 & 7.90 & 0.08 \\
\hline Time Series 2009-12 & 7.86 & 7.88 & 7.87 & 7.87 & 0.00 \\
\hline Time Series 2012-15 & 6.96 & 9.31 & 7.96 & 7.64 & 0.11 \\
\hline
\end{tabular}


Time Series Forecasting Of Water Quality Of River Godavari

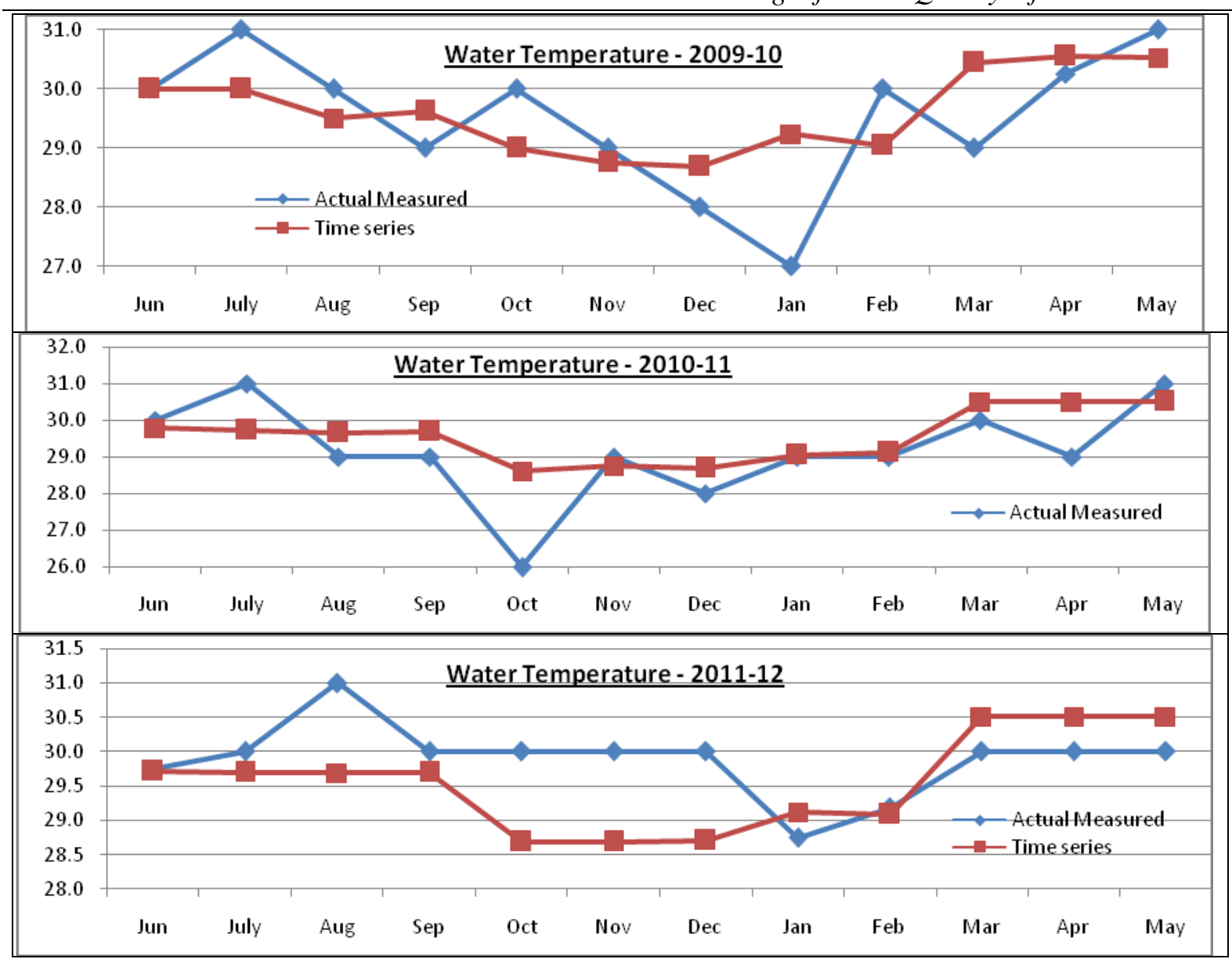

Figure 2(a): Graphs showing the variations of Water Temp during the study period (2009-12)

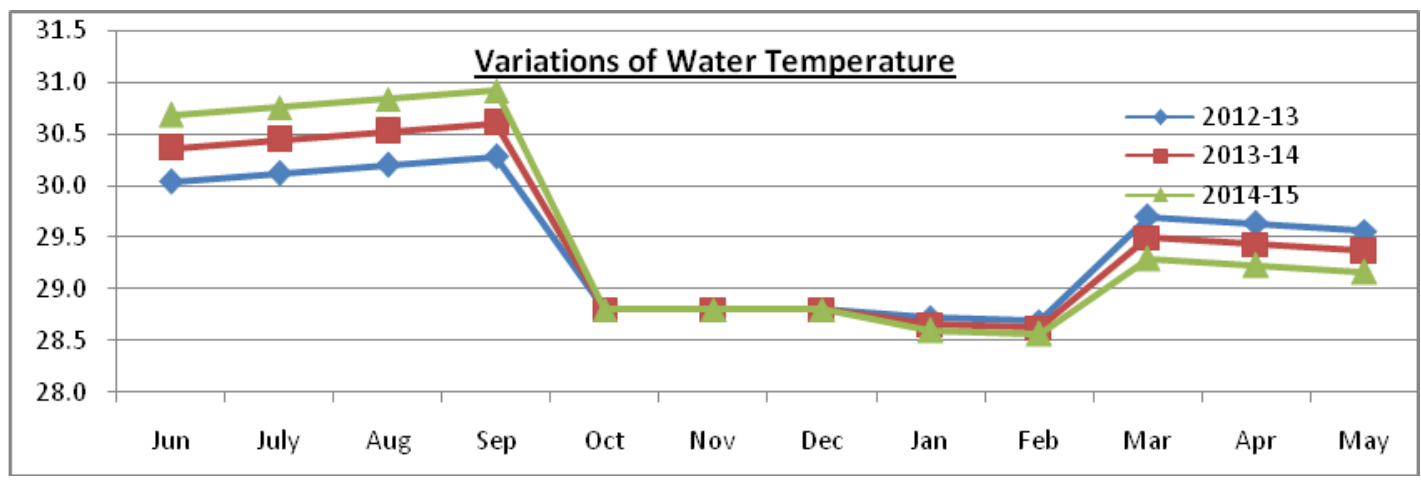

Figure 2(b): Graph showing the variations of Water Temp during the Future Period (2012-2015)

\subsection{Dissolved Oxygen Model}

Dissolved Oxygen content is one of the most important factors in stream health. Its deficiency directly affects the ecosystem of a river due to bioaccumulation and biomagnifications. Fluctuations of DO values occur due to industrial, human and thermal activity. The amount of oxygen that can be held by the water depends on the water temperature, salinity, and pressure. DO levels below 1ppm will not support fish; levels of 5 to $6 \mathrm{ppm}$ are usually required for most of the fish population. The average value of DO levels $(6.5 \mathrm{mg} / \mathrm{l})$ indicates the average quality of river water (APHA 2005).

The seasonal variations of the predicted time series and actual measured values are shown in Fig 3(a) and $3(\mathrm{~b})$. The descriptive statistics of the DO values are tabulated below. Variations occurred among the predicted and actual measured values. The historic data was used for predicting the time series values. The variations in the reported values of the historic data (upto 2009 May)and the actual measured values during the study period (2009-2012) resulted in the variations that occurred. The results of the statistical performance test revealed that the $\mathrm{MAE}=0.94, \mathrm{RMSE}=1.18$ and $\mathrm{MAPE}=3.24$; which shows that the predicted models are reliable. A decreasing trend was observed during Southwest monsoon (Jun to Sep) and Northeast monsoon (Oct to Dec) 
Time Series Forecasting Of Water Quality Of River Godavari seasons and an increasing trend was observed during the winter (Jan to Feb) and summer (Mar to May) seasons respectively. Hence it may be concluded that though decreasing and increasing trends are observed, the Dissoilved oxygen levels are above permissible limits.

Table3: Descriptive statistics of D.O. Study period (2009-2012) and Future period (2012-2015)

\begin{tabular}{|c|c|c|c|c|c|}
\hline \multirow{2}{*}{ Developed Model } & \multicolumn{5}{|c|}{ Descriptive Statistics of Dissolved Oxygen } \\
\cline { 2 - 6 } & Min & Max & Mean & Std. Dev & Var. \\
\hline Actual Measured & 6.1 & 8.3 & 7.40 & 7.56 & 0.09 \\
\hline Time Series 2009-12 & 6.3 & 8.0 & 7.20 & 7.10 & 0.08 \\
\hline Time Series 2012-15 & 6.5 & 9.8 & 7.70 & 7.15 & 0.17 \\
\hline
\end{tabular}

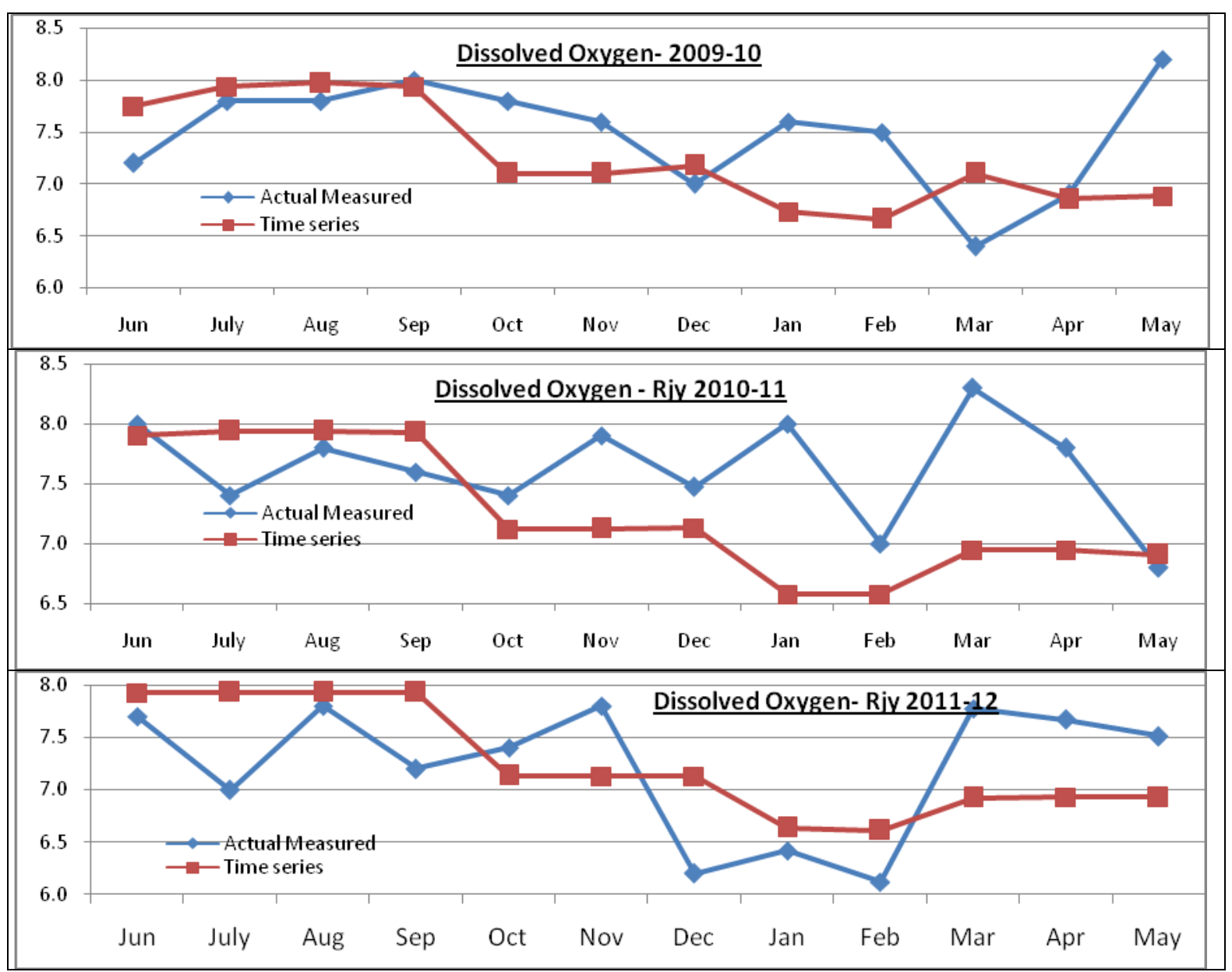

Figure 3(a): Graphs showing the variations of Dissolved Oxygen during the study period (2009-2012)

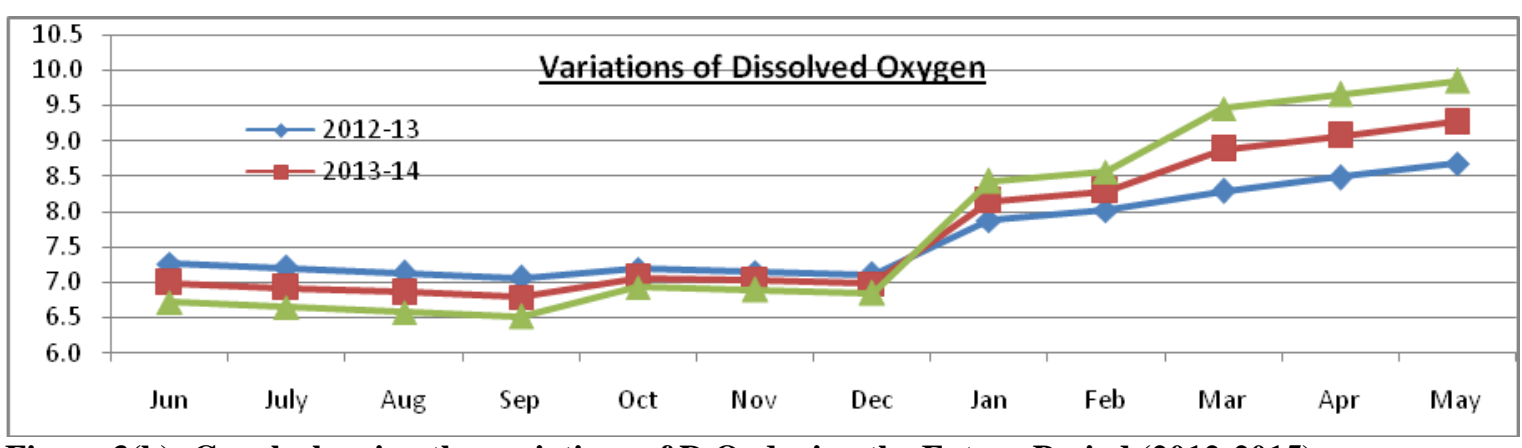

Figure 3(b): Graph showing the variations of D.O. during the Future Period (2012-2015) 
V. Conclusion:

The results of the study indicated that the developed models performance was significant. The statistical performance test results indicated the reliability of the developed models. It may be stated that differences in the ranges of values reported in the historic data adopted for time series forecasting and the actual measured values during the study period are responsible for the variations that occurred. The Time series model predicted the parameters three years ahead using the historic data. But when comparing the predicted values with actual measured values during the study period, variations occurred. These variation are a result of the degradation of quality that have occurred during the present period. Though the variations occurred between the predicted and observed values, the forecasted values of the parameters are reliable and accepted if the error is within permissible limits. Finally it is concluded that the water quality data exhibited seasonal variations and identical trend pattern. Time series forecasting of future water quality conditions is an important measure to take up necessary measures to preserve the water quality of Rivers.

\section{References:}

[1]. Najafpour.Sh et al., 2008; "Evaluation of Spatial and Temporal Variation in River Water Quality” Int. J.Environ.Res 2(4) 349-358 autumn 2008

[2]. Priyanka Trivedi et al.,2009; "Evaluation of Water Quality : Physio-Chemical Characteristics of Ganga River at Kanpur by using Correlation Study" Naure and Science, 2009:1(6) P91-94.

[3]. Nikhil Raj and P.A.Azeez 2009 "Spatial and Temporal variations in surface water chemistry of a tropical river, the river Bharatapuzha, India; Current Science Vol 96 No:2 P 245-250.

[4]. Muhamed Ashraf.P and M.K.Mukundan 2007; "seasonal Variations in water quality of four stations in the Periyar River Basins" J. Env Sci \& Engg Vol 49 No 2, P127-132.

[5]. A.G.Murugesan et al ., 2007 ; “ Physio -chemical and Biological study of the River Chittar at Courtallam, TamilNadu (India) J. Env Sci \& Engg Vol 49 No 2, P121-126.

[6]. Mariappan., et al., 1998. Surveliance of ground water quality in Thiruppanur block of Sivagangai district. Indian J Envron Prot. 19(4) : 250-254

[7]. Miller, W.W.Joung, et al., 1986. Identification of water quality differences in Nevada through index application. J.Environ Quality $15,265-272$.

[8]. N. Singkran, et al., 2010, Determining water conditions in the Northeastern rivers of Thailand using time series and water quality index models, Journal of Sustainable Energy \& Environment 2010;47-58.

[9]. Rita .N.Kumar, et al., 2009, An assessment of seasonal variation and water quality index of Sabarmati River and Kharicut canal at Ahemadabad, Gujarat; Electronic journal of environmental, agricultural and food chemistry, 2011; 2248-2261.

[10]. Tiwari, T.N. and ,Mishra.M., 1985. A preliminary assignment of water quality index to major rivers Ind J Environ Prot. 5: 276

[11]. Ashwani Kumar and Anish Dua, 2009, Water quality index for assessment of water quality of River Ravi at Madhopur. Global Journal of Environmental Sciences Vol. 8 No.1, 2009: P 49-57 